\title{
BMJ Open What are the needs and preferences of patients and family members discharged from the emergency department within 24 hours? A qualitative study towards a family-centred approach
}

\author{
Christina Østervang (D) , ${ }^{1,2}$ Annmarie Touborg Lassen (D) , , \\ Charlotte Myhre Jensen (D) ,2,3 Elisabeth Coyne (D) ,2,4 \\ Karin Brochstedt Dieperink (iD) 2,5
}

To cite: Østervang C, Lassen AT, Jensen CM, et al. What are the needs and preferences of patients and family members discharged from the emergency department within 24 hours? A qualitative study towards a familycentred approach. BMJ Open 2021;11:e050694. doi:10.1136/ bmjopen-2021-050694

- Prepublication history and additional supplemental material for this paper are available online. To view these files, please visit the journal online (http://dx.doi.org/10.1136/ bmjopen-2021-050694).

Received 01 March 2021 Accepted 20 0ctober 2021

\section{Check for updates}

\section{(c) Author(s) (or their} employer(s)) 2021. Re-use permitted under CC BY-NC. No commercial re-use. See rights and permissions. Published by BMJ.

For numbered affiliations see end of article.

Correspondence to Christina Østervang; christina.oestervang.nielsen@ rsyd.dk

\section{ABSTRACT}

Objective There is an increase in patients being discharged after short stays in the emergency department, but there is limited knowledge of their perspectives on treatment and care. This study aims to explore and understand the needs and preferences of emergency care from the perspective of patients and family members discharged from the emergency department within 24 hours of admission.

Design The study reports from the first phase in an overall participatory design project. Systematic text condensation was used to identify key themes from field observations and interviews with patients and family members.

Setting This study was conducted in two emergency departments in the Region of Southern Denmark. Participants All adults aged $\geq 18$ years who had been discharged from the emergency department within 24 hours were eligible to take part. Purposeful sampling was used to recruit patients and family members with different sociodemographic features.

Results Field observational studies ( $\mathrm{n}=50$ hours), individual interviews with patients $(\mathrm{N}=19)$ and family members $(\mathrm{N}=3)$, and joint interviews with patients and family members $(\mathrm{N}=4)$ were carried out. Four themes were derived from the material: (1) being in a vulnerable place — having emotional concerns; (2) having a need for person-centred information; (3) the atmosphere in the emergency department and (4) implications of family presence.

Conclusion This study demonstrates a gap between patients and family members' needs and preferences and what current emergency departments deliver. The findings highlight the importance of family and person-centred care. Tailored communication and information with genuine involvement of family members is found to be essential needs during acute illness.

\section{INTRODUCTION}

Internationally, many countries comparable to Denmark, such as the UK and Australia, work to establish an organisational structure in emergency departments (ED) to prevent overcrowding and access blockage. ${ }^{1}$ A 4-hour

\section{Strengths and limitations of this study}

- The findings and methodological approaches in the study have been critically evaluated and discussed by experienced researchers from different fields of research.

- Data were generated using different methods and involved a broad representation of participants to ensure robust findings.

- Quotations support the trustworthiness of the findings.

- Although there is a thorough description of the research process to support credibility, descriptions of the findings are contextual and reflect a Danish context.

rule was introduced in EDs for practitioners to develop a plan of treatment: either admission or discharge was expected within 4 hours. ${ }^{1}$ Across 21 Danish EDs, the same structure exists to promote clinical assessment and treatment plans of patients within 4 hours, a short stay in a Danish ED typically range from $<4$ to 48 hours. $^{2}$ However, a lack of thoroughness in the delivery of information and assessment of patients' and family members' individual needs may result in patients being discharged from the ED who are unable to maintain their health status. ${ }^{34}$ The environment in EDs is challenging, with a diversity of health needs to be met. ${ }^{5}$ Key concerns were identified by patients including, understanding their condition, symptom relief, reassurance and a treatment plan. ${ }^{67}$ However, the focus was on patient-reported measures to improve acute care and did not include the family perspective. ${ }^{6}$ Interventions related to patient outcomes are limited or focus on 
reducing readmission rather than satisfying needs and preferences. ${ }^{8}$

Globally, many initiatives focus on out-of-hospital care, such as hospital at home, telehealth and outpatient clinics to support ongoing treatment initiated in the hospital as well to support early discharge.${ }^{910}$ In this care, family members play an active role in maintaining patient outcomes after early discharge to homes. ${ }^{11}{ }^{12}$ Mackie $e t$ al found in a qualitative study that health professionals identified the advantage of family participation in care for enhancing the quality of care and improving patient satisfaction. ${ }^{1314}$ However, research on the needs of family members involved in short visits to EDs is sparse or focuses on elderly patients. ${ }^{15} 16$ To date, little is known of how patients and families experience short-term stays in the ED and what needs and preferences they have. ${ }^{17} 18$ In the interest of organising and practising tailored care, it is essential to explore the needs and preferences of patients and their family members to ensure that the care provided is valuable.

\section{Objective}

This study aims to explore and understand the needs and preferences of emergency care from the perspective of patients and family members discharged from the ED within 24 hours of admission.

\section{METHODS}

\section{Study design}

Participatory design (PD) is this study's overall research methodology. ${ }^{19} \mathrm{PD}$ has a phenomenological and hermeneutical stance using qualitative methods to understand lived experiences and needs of individuals. ${ }^{19} 20$ As methods, field observations and interviews with patients and family members were chosen. This study reports from the first phase of a three-phased PD project. $^{21}$ Consolidated criteria for Reporting Qualitative research: a 32-item checklist for interviews and focus groups was used as guidelines. ${ }^{22}$

\section{Patient involvement}

The local patient and family member council have read the study protocol and gave suggestions for improvements, for example, regarding sampling strategy and clarity of the patient population included in the study.

\section{Setting}

The study was conducted in EDs at two hospitals in the Region of Southern Denmark:

1. Odense University Hospital: a 1000-bed university hospital that covers all specialties. The ED has 69000 annual attendees. On average, 32 patients are admitted per day, and $50 \%$ are discharged within 24 hours.

2. The Department of Emergency Medicine, Hospital of Lillebaelt, Kolding: The Hospital of Kolding has 320 beds. The ED has 50000 annual attendees and receives 146 patients per day. Visitor restrictions due to

\begin{tabular}{|c|c|}
\hline \multicolumn{2}{|l|}{ Patients $(n=20)$} \\
\hline Age & $\begin{array}{l}10 \text { patients } \geq 65 \text { years of age } \\
10 \text { patients } \leq 65 \text { years of age }\end{array}$ \\
\hline Sex & $\begin{array}{l}10 \text { females } \\
10 \text { males }\end{array}$ \\
\hline Symptoms & $\begin{array}{l}10 \text { patients having surgical symptoms } \\
10 \text { patients medical symptoms }\end{array}$ \\
\hline Education level & $\begin{array}{l}10 \text { patients with education level above } \\
\text { secondary school } \\
10 \text { patients with education level below } \\
\text { secondary school }\end{array}$ \\
\hline Function level & $\begin{array}{l}10 \text { patients receiving primary care } \\
10 \text { patients not receiving primary care }\end{array}$ \\
\hline $\begin{array}{l}\text { Social status } \\
\text { Frequency of stay }\end{array}$ & $\begin{array}{l}10 \text { living on their own in independent } \\
\text { accommodation } \\
10 \text { living together with someone } \\
10 \text { having their first visit in the ED } \\
10 \text { having more than one visit in the } \\
\text { ED }\end{array}$ \\
\hline
\end{tabular}

ED, emergency department.

COVID-19 were in place in 2020, and only one family member per patient was allowed to accompany the patient in the ED.

\section{Participants}

\section{Eligibility criteria}

Patients were Danish-speaking individuals $\geq 18$ years old with a medical or surgical diagnosis who had been discharged from the ED after less than 24 hours. Family members accepted by the patient were included.

\section{Exclusion criteria}

Patients with cognitive impairment as evaluated by an individual clinical judgement according to their ability to comprehend the terms of participating were excluded. Patient triaged at the highest and lowest triage level as per the Danish Emergency Process Triage were excluded. ${ }^{23}$ The highest triage level is received care in trauma room and not expected to be discharged within 24 hours. The lowest triage level is received care for minor cut or concern by either a nurse or a physician with no examinations.

\section{Sample size}

The minimum sample was 20 patients. Data collection continued until thematic saturation ${ }^{24}$ and a predefined target group obtained (table 1). No specific target sample was set for family members. Features were defined by the research group to ensure diversity represented.

\section{Data collection}

Data collection was carried out by $\mathrm{C} \varnothing$, who has 13 years of experience in nursing and holds a master of science in nursing. She had no care responsibilities for any of the patients admitted to the ED. 
Researcher characteristics and reflexivity

A phenomenological-hermeneutical approach allowed CØ to recognise her perceptions as an experienced emergency nurse within hermeneutic interpretation. ${ }^{25} \mathrm{To}$ enable recognition of the researchers preconceived ideas $C \varnothing$ wrote down her preunderstanding of why patients lack information being discharged and might have many concerns. ${ }^{26}$ This reflection provided an initial focus for research questions. ${ }^{26}$

\section{Recruitment}

Eligible patients and their family members were purposively recruited between 9 August 2020 and 29 October 2020, by the first author (CØ). In both EDs, a nurse coordinator keeps an overview of available rooms, in and out hospital transfers and expected length of stay for each patient in close collaboration with the emergency physicians. CØ discussed the target group population with the nurse coordinator to identify potential participants. No time restriction related to how long the patients had stayed in the ED was set besides a criterion of discharge before 24 hours of admission. If the patient was not discharged as expected they were excluded from the study. After identifying a potential participant $C \varnothing$ talked to the nurses who provided the care and they asked for the patient's permission for $C \varnothing$ to approach the patient. If accepted, CØ informed the patient and/or family members orally and in writing about the study. At the end of the observation all participants were asked for consent for one interview within the first week after discharge.

\section{Field observational studies}

Field observations helped the authors to understand how the interactions and activities in the ED informed experiences, needs and preferences. ${ }^{25}$ Furthermore, it provided first-hand knowledge of consistency between what actually happened during the participants interaction with health professionals in emergency and what was said by participants in the interviews. ${ }^{25}$ Inspired by Spradley's nine dimensions, ${ }^{27}$ an observational guide was designed and pilot-tested in two cases. The observational guide contained several points including human interactions, time and events in the ED. CØ was present at the EDs for 3-6 hours per day, during both morning and evening shifts, and made observations in medical and surgical areas. $C \varnothing$ followed the patients during their stay joining them in the hospital room, examinations and other areas the participant required treatment. Duration of the observations varied in respect for the patient's wishes from $30 \mathrm{~min}$ to 4 hours. Field notes were written each day containing observations and quotes.

\section{Interviews}

To gain an understanding of the needs and preferences interviews extended the observation data. Both individual and joint interviews were used, as the study aimed to explore both the perspectives of the patients and family members as well as their joined needs. The authors wanted to give the participants the power to decide which interview style they preferred. Therefore, interviews were conducted as face to face, telephone, individual or joint interviews according to participant preference and to accommodate the COVID-19 induced restrictions. All interviews were conducted using an interview guide inspired by Kvale and Brinkmann, ${ }^{28}$ recorded and transcribed. The guide was developed based on the identified scientific literature on the topic and the preliminary results of field observations. An example of an interview question is: "What significance does family have in your lives?'

Data from the observations were used directly in the interview, for example, 'At the end of the stay you talked to a nurse, can you tell me about that experience?'

At the end of the interview, the interviewer summarised the interview and checked with the participant to ensure correct interpretation. Participants were asked if they would like to read the transcript. Two participants accepted with no further comments. The interview guide was pilot tested with two cases. Interviews were conducted one time, 2-7 days after discharge.

\section{Analysis}

The analysis was performed according to systematic text condensations four steps. ${ }^{29}$ An overall caption was initially made of the data to extract dominant themes. This was followed by dividing dominant themes into meaningful topics. Finally, the data were coded to put meaningful topics into categories. Field observational data were used to support interview data. The data from field observations and the interviews were analysed separately and then combined across the participant interaction to understand the deeper aspects of health professional interchanges with participants and the participants recollection of the interaction and information. After this process, all data were synthesised. CØ was in charge of the coding process. During the coding process the author group met to discuss the codes as strategy to mitigate potential bias. Credibility was also enhanced by the analysis being conducted using investigator triangulation, as data were continuously discussed with all co-authors. NVivo V.12 was used to store, code and systematise data.

In accordance with the Declaration of Helsinki and the Ethical Guidelines for Nursing Research, ${ }^{30}$ participants were asked both orally and in writing to grant consent. The study is registered with the 'Record of data process of Registry of Southern Denmark' (19/22672). Data were stored in SharePoint (Microsoft) AND OPEN_938.

\section{RESULTS}

\section{Participant descriptions}

Field observational studies were conducted for 20 days (50 hours total; August to October 2020). Twenty-eight patients were asked permission to participate in the study, and four declined due to mental distress. Twentyfour patients accepted participation (table 2); however, 
Table 2 Characteristics of participating patients

\begin{tabular}{|c|c|}
\hline Patient characteristics & $\mathbf{N}(\%)$ \\
\hline \multicolumn{2}{|l|}{ Gender } \\
\hline Male & $9(37.5)$ \\
\hline Female & $15(62.5)$ \\
\hline \multicolumn{2}{|l|}{ Age } \\
\hline $1-35$ & $3(12.5)$ \\
\hline $36-49$ & $5(20.8)$ \\
\hline $50-65$ & $5(20.8)$ \\
\hline $66-80$ & $6(25.0)$ \\
\hline 81 or older & $5(20.8)$ \\
\hline \multicolumn{2}{|l|}{ Living situation } \\
\hline Living alone & $11(45.8)$ \\
\hline Living with others & $13(54.2)$ \\
\hline Nationalities represented in the study & $4(100)$ \\
\hline \multicolumn{2}{|l|}{ Education level } \\
\hline Below secondary school & $11(45.8)$ \\
\hline Above secondary school & $13(54.2)$ \\
\hline \multicolumn{2}{|l|}{ Function level } \\
\hline Receives primary homecare & $9(37.5)$ \\
\hline No help needed & $15(62.5)$ \\
\hline \multicolumn{2}{|l|}{ Method of admittance } \\
\hline By ambulance & $15(62.5)$ \\
\hline Attending the ED alone & $5(20.8)$ \\
\hline Attending the ED with family members & $4(16.7)$ \\
\hline
\end{tabular}

Family in the ED

\begin{tabular}{lr} 
Yes & $13(54.2)$ \\
\hline No & $11(45.8)$ \\
\hline Frequency of stay & $9(37.5)$ \\
\hline First time in ED & $15(62.5)$ \\
\hline More than one visit in the ED & \\
\hline Main symptoms & $10(41.7)$ \\
\hline Medical & $6(25.0)$ \\
\hline Surgical & $3(12.5)$ \\
\hline Neurological & $4(16.7)$ \\
\hline Orthopaedic & $1(4.2)$ \\
Gynaecological & \\
\hline Comorbidity & $13(54.2)$ \\
\hline Yes & $11(45.8)$ \\
\hline No
\end{tabular}

ED, emergency department.

one patient did not respond to the telephone call. Seven family members accepted (table 3). Nineteen individual interviews were conducted with patients, three with individual family members and four as joint interviews patient and family. To achieve enrollment across all target groups, recruitment continued until 24 patients were enrolled.
Table 3 Characteristics of participating family members

\begin{tabular}{lc}
\hline Family member characteristics & N (\%) \\
\hline Gender & \\
\hline Male & 4 \\
\hline Female & 3 \\
Mean age (years) & 55 \\
\hline Family relation to patient & \\
Daughter & 1 \\
Son & 1 \\
Spouse & 4 \\
Parent & 1 \\
Education level & \\
Below secondary school & 3 \\
Above secondary school & 4 \\
\hline
\end{tabular}

Interviews were conducted at a convenient location for the patient and/or family, either by telephone $(n=23)$ or at the patient's home $(n=3)$.

Four themes were developed:

1. Being in a vulnerable place- having emotional concerns.

2. Having a need for person-centred information.

3. The atmosphere in the ED.

4. The implications of family involvement.

\section{Being in a vulnerable place: having emotional concerns}

Most of the patients expressed a sense of vulnerability while attending the ED. Some patients had been to the ED several times, but that did not necessarily make them more confident. Patients described feelings such as stress, anxiety and being afraid of what was going to happen. Only a few patients shared their emotional thoughts with HCPs (nurses or physicians at the ED) Both patients and family members highlighted that they had the need for an approach that showed an understanding of their emotional concerns alongside physical symptoms.

I was admitted late in the evening yesterday. It is my third time here... Actually, I have been terrified since last time... You know, psychologically scared... (Informal interview during field observation, female patient in her 60s).

Similar for patients and family members was the need for clear signals from HCPs. When finding themselves in such a stressful and tense situation, they wanted HCPs to navigate them through their stay in the ED by being precise and direct when communicating. Patients described the need for knowing what they were waiting for, as otherwise, unproductive thoughts about being severely ill came to their minds in addition to feelings of being forgotten by HCPs.

Waiting time is hard... You do not know what is happening, and you speculate if they (HCPs) soon will 
find out... I am all alone with my thoughts (female patient in her 80s).

The majority of the patients underlined that the stay in the ED was only a small part of their trajectory; the time before attending the ED could have been very exhausting, and the time after discharge was filled with concerns or doubt related to the progress of the illness, new medication and follow-ups.

She talks in the phone. She says that no one asked if she was able to handle things at home. 'But I need home care, how do we do this?' she asked her family during the phone conversation (fieldnote, October 2020).

Patients expressed that they were in a blurry state of mind, not able to remember details when returning to home. They preferred a follow-up at their general practitioner, looking into the electronic record app from home or having family to help them remember elements in the treatment plan after discharge. Even if nurses and physicians strived to be thorough in communicating discharge information, patients seemed not to be able to remember things such as where to go for follow-up, what to do if they started feeling worse, future treatment plans or how to manage new medication.

The physician is having a long conversation with him. Pleasant atmosphere. They both smile. They have eye contact. They agree on the plan of discharge (fieldnote, August 2020).

I only remember that I was not allowed to drive, but actually I do not know for how long? (Patient talking about his experience reflected in the fieldnote, male in this $60 \mathrm{~s}$ ).

Some patients explained that they had information overload in a very short period of time, and in relation to finding themselves in an unbalanced situation, they could not process as much as they normally would be able to. There was no difference in this sense across different ages. Family members did not describe the same issues.

At that time, I did not realise, I had to ask when and how I should take the new medication... I had to call the ED the day after (female patient in her 40s).

\section{Having a need for person-centred information}

Both patients and family members emphasised a desire for more information. Especially, the patients preferred having things repeated frequently in plain language. Moreover, the uncertainty of being acutely ill seemed to intensify a need for knowing when changes in the treatment plan are made. Both patients and family members would have preferred a system where they could follow 'live' updates of the journal.

The patient and her husband talk about wanting access to the electronic journal while we are in the hospital (fieldnote, September 2020).
The participants expressed understanding of the limited time available to provide information when the department was busy but underlined that their need for information was still valid.

There I was, about to explode. I kept myself in control and asked if anyone had thought about telling ME about the changes in the plan. I had waited for eighthours, and I was apparently the only one who did not know that the planned examination was changed (female patient in her 30s).

Those patients who found their information needs fulfilled described that HCPs had resources to collect the patient-reported data, listen to the patient in a genuine way, and inform them about expected examinations at the same time.

When the pictures from the scan were ready, the physician sat beside me and commented on them in a way that I could understand. It could not have been done better (male patient in his $80 \mathrm{~s}$ ).

Experiences that helped patients and family members alleviate their burdens were related to information and communication levels. Patients preferred communication from HCPs to be provided in a clear and concise way. Lack of confidence from the HCP negatively affected how patients were able to deal with their situations.

The insecurity the physician came in with... He was so shy and cautious... In this situation, I had the need for him to step forward and say: 'We are going to do this and this... and we have everything in control.' He failed to relieve the stress I was carrying on my shoulders (male patient in his 50s).

Being chronically ill appeared to present diverse information needs. Family members and patients dealing with chronic disease expressed a need for HCPs to listen to them and plan a treatment linked to their previous experiences. Patients preferred to see experienced nurses and physicians being able to handle symptoms and begin treatment without the need for consulting more experienced colleagues.

It is like they follow a manual instead of listening to me. Sometimes I just take the medication they always offer, even though I know, and have told them many times, that it does not take away MY pain (female patient in her 40s).

\section{The atmosphere in EDs}

Aspects of a 'busy environment' were mentioned by all participants. Situations where patients were discharged by the physician but still waited for details on things like medications delayed them leaving the hospital. The patients described an uncomfortable sense of disturbing the nurse, as they knew they were busy, but on the other hand, they saw possibilities of making room for new patients if they just were given the details needed. 
She looks at me and says: why is she (the nurse) not coming as we agreed to...should I call for her again.... Maybe she gets angry with me.... She calls for the nurse again (fieldnote, September 2020).

Being a patient in a busy environment provided insecurity if HCPs did not share which examinations were initiated, what the progress on these was, and what the estimated time was before a treatment plan could be formed. They found themselves trapped in a worrying situation with no options to find answers to clarify their speculations. Better clarity of the progress was primary preferred by the patients.

I tried many times to find out if the scan was booked. No one wanted to say anything... I know there must be some priority lists, but where I am on that? No one seemed to want to talk to me... I just wanted an estimate of how long it would take... That uncertainty-I really hope the time spent being uncertain could be reduced (male patient in his $50 \mathrm{~s}$ ).

The participants highlighted how the HCPs' attitudes influenced how their needs were fulfilled, describing an ideal connection with the HCP as involving being seen as a person rather than 'just another patient in the row'. Negative attitudes also seemed to affect the time after discharge, as it entailed a need for processing the experience through conversation and discussion of the encounter.

It was frustrating that the physician, a new one, came to send us home... He started to complain about how this was not his intended job, as he worked in another area of the hospital... That was frustrating to be met in that way and we talked a lot about his attitude after returning to home (husband in his $40 \mathrm{~s}$ ).

\section{Implications of family involvement}

The participants explained that family presence in EDs provided support. Often, patients found themselves in a position where it was difficult to explain and keep track of details of what had happened before the acute symptoms occurred, and family members were able to provide those details.

I was pretty blurry, but my husband could tell them (HCP) about the past days, the operation and so on; that made me calm (female patient in her 50s).

Family members of patients who had been in the ED many times could feel great frustration when their loved ones were discharged rapidly without any interventions or further treatment plans. They described a feeling of powerlessness without any means to affect the way forward, and they asked for a clear treatment plan or symptom control.

One time I went with her... I thought, now I really had to tell them... But I could not do anything...
Nothing helped... We were sent home as all the other times (husband in his 40s).

In many cases, family members played a central role after discharge. The patients who did not have family members nearby arranged for supportive telephone calls from neighbours or primary homecare. In some instances, the nurses in the ED recognised the patient's need for extra support after discharge, but this was the result of individual judgements by the nurses.

A nurse enters the hospital room, she tells the patient that she has tried to reach the primary homecare by phone but did not succeed. She asks if the patient could call them herself when she comes home (fieldnote, October 2020).

Family members described a need to be heard and genuinely involved in discharge plans and patients preferred if they had family they would like to involve. Family members who were not able to be physically present during the emergency admission stressed that they would like to be included in discussions regardless.

They did not listen to me; it was way too soon (to discharge). When we came home, it got worse. I couldn't even get her to the bathroom. I called 112 again, I couldn't handle the situation (son in his 50s).

\section{DISCUSSION}

\section{Principal findings}

We investigated the needs and preferences of patients discharged from the ED and their family members and found that they wanted health professionals to understand their vulnerability. They also preferred HCPs to engage in direct communication that was tailored to their level of understanding-especially information on waiting times and treatment plans. The busy environment caused doubts about control of their treatment plan and provided feelings of being 'just another patient' in the line. No specific strategy for including family in the interactions with health professionals was observed, however, a need for genuine family involvement in discharge plans was identified.

\section{A gap between needs and organisation}

Research has explored interventions to reduce overcrowding in the ED, placing a focus on patient flow and effective organisation. ${ }^{31} 32$ These changes might have a psychosocial cost, however, as we identified a gap between the needs of patients and family members and what the healthcare system currently delivers. Patients have several unmet needs, including information and psychosocial support during a time of vulnerability. A need for clear communication has also been found in previous research. ${ }^{33-35}$ A protocol for discharge communication in the ED, could support and train HCPs to possess person-centred communication 
skills. ${ }^{33}$ Moreover, implementing a "protected and undisturbed time' for HCPs when entering a discharge conversation. ${ }^{34}$ This could be a possible solution to reduce the gap between an effective and flow-focused environment and the need for clear communication. Patients reported difficulties remembering the provided information. Lack of recall caused patients to contact the ED, see their general practitioner or look at the electronic record app to understand instructions. Interventions to improve patient understanding after discharge were previously initiated in a qualitative American study, which suggested that patients follow-up at home and revisit information. ${ }^{36}$ However, these findings differ from a Danish randomised study by Lisby et al, which explored services such as telephone follow-up and discharge letters. ${ }^{8}$ They found that telephone follow-up did not show a significant effect on patients' experiences of discharge. ${ }^{8}$ These interventions did not seem to reduce the gap between patient needs and what the current healthcare system is able to deliver.

A main finding in our study was the need to identify the vulnerability of the patients and family. Therefore, we suggest that future interventions include tailored communication and a person-centred approach based on an understanding of the underlying sense of vulnerability acute patients and family members suffer from. Vaillancourt et al developed a conceptual model of ED care in which they found that patients have a need for HCPs to recognise their emotional worries. ${ }^{6}$ A meta-synthesis on ED patient experience found that the ED information must be tailored to patients if their emotional needs are to be met. ${ }^{37}$ They emphasised a request for knowledge about 'patient suffering' from anxiety and fear in the ED and its implications. ${ }^{37}$ In parallel, a Danish study exploring hip-facture management also identified a gap between what the healthcare system provides, and patients' needs when they are in a shock-like state of mind. ${ }^{38}$ Similar to our findings, they stressed a need for more individual targeted means of informing and educating patients to meet their needs. ${ }^{38}$

Therefore, our findings create an awareness of the vulnerable state of mind acute patients possess. From this knowledge, the feasibility of developing future interventions to accommodate needs in the $\mathrm{ED}$ might be improved.

\section{A need for genuine family involvement in the ED}

Family members in our study described a need for genuine involvement and recognition by HCPs. Family members play a central role during a patient's illness. They help patients 'translate' care and need to be included in treatment and care planning. Similar research has reported that family members are recognised as a resource in the ED. ${ }^{11} 39$ Family members can assist with practical and emotional support, but direct involvement in care is lacking, especially in busy periods. ${ }^{110}$
A lack of genuine involvement was also identified in our study, resulting in frustrations and feelings of powerlessness. Our findings highlight that for family members to be a resource, they need to be involved in discussions to ensure fundamental details related to the patient course of treatment are not missed, leading to readmission. To promote genuine family involvement in care, a systematic approach towards family inclusion should be introduced and HCPs trained in family-focused communication. ${ }^{41}{ }^{42}$ Genuine involvement with families might reduce the uncertainty associated with the illness experience and increase the ability to self-manage at home. ${ }^{43}$ One strength of our study was the triangulation of patient and family member perspectives combined with field observations. This introduces a broad perspective into the research. The inclusion of two sites with no notable differences in participants' statements further strengthens the validity of the findings. The study constitutes an important and crucial step towards an understanding of how to design interventions to improve family-centred care. The next phase of this three-phased study will be a codesign development of an intervention to meet the needs of patients and family members.

\section{Limitations}

Data collection by a single researcher was a potential bias but also ensured reliability in data collection. An observational guide and a systematic analysis process was followed to reduce the risk of bias. ${ }^{44}$ Moreover, methodological and investigator triangulation were applied to support credibility. ${ }^{44}$ Telephone interviews prevented the interviewer from seeing facial expressions and body language, which reduced the ability to clarify answers if uncertainty. ${ }^{28}$ Only family members at the hospital were recruited, leading to a small sample size and also potential selection bias. Having a strategy for recruiting family members not physically present in the hospital might have given a broader aspect into the family perspectives. For future research similarities and differences in the needs of patients and family members could create a broader understanding of emergency care. Furthermore, we did not include patients with cognitive impairment due to the complexity of the patient category; this is suggested for future research.

\section{CONCLUSION}

This study demonstrates that there is a gap between the needs and preferences of patients and family members and what the ED delivers. The findings highlight patient and family members need an increased understanding on them being in a vulnerable state of mind. They have a need for person-centred information with genuine involvement of family members.

\section{Author affiliations}

${ }^{1}$ Department of Emergency Medicine, Odense University Hospital, Odense, Denmark ${ }^{2}$ Clinical Institute, University of Southern Denmark Faculty of Health Sciences, Odense, Denmark 
${ }^{3}$ Department of Orthopedic Surgery and traumatology, Odense Universitetshospital, Odense, Denmark

${ }^{4}$ Nursing, Griffith University Faculty of Health, Brisbane, Queensland, Australia

${ }^{5}$ Department of Oncology, Odense University Hospital, Odense, Denmark

Twitter Christina Østervang @C_Oestervang and Elisabeth Coyne @ Elisabethcoyne1

Acknowledgements The authors would like to thank patients and family members for spending time participating in this study.

Contributors CMJ, KBD, EC, ATL and CØ designed the study. $\varnothing \emptyset$ collected data. CMJ, KBD and $C \emptyset$ performed the analysis. $\varnothing \emptyset$ took the lead in drafting the manuscript; all authors commented and gave feedback. All authors approved the final version of the manuscript. $C \emptyset$ is guarantor of the study.

Funding This work is supported by Odense University Hospital, Region of Southern Denmark and The University of Southern Denmark. Grant numbers: N/A.

Competing interests None declared.

Patient consent for publication Not applicable.

Ethics approval According to Danish legislation, this study did not need ethical approval from the National Committee on Health Research Ethics (REF: S-20192000-111).

Provenance and peer review Not commissioned; externally peer reviewed.

Data availability statement Data are available on reasonable request.

Supplemental material This content has been supplied by the author(s). It has not been vetted by BMJ Publishing Group Limited (BMJ) and may not have been peer-reviewed. Any opinions or recommendations discussed are solely those of the author(s) and are not endorsed by BMJ. BMJ disclaims all liability and responsibility arising from any reliance placed on the content. Where the content includes any translated material, BMJ does not warrant the accuracy and reliability of the translations (including but not limited to local regulations, clinical guidelines, terminology, drug names and drug dosages), and is not responsible for any error and/or omissions arising from translation and adaptation or otherwise.

Open access This is an open access article distributed in accordance with the Creative Commons Attribution Non Commercial (CC BY-NC 4.0) license, which permits others to distribute, remix, adapt, build upon this work non-commercially, and license their derivative works on different terms, provided the original work is properly cited, appropriate credit is given, any changes made indicated, and the use is non-commercial. See: http://creativecommons.org/licenses/by-nc/4.0/.

\section{ORCID iDs}

Christina Østervang http://orcid.org/0000-0001-5990-0167

Annmarie Touborg Lassen http://orcid.org/0000-0003-4942-6152

Charlotte Myhre Jensen http://orcid.org/0000-0002-7058-4641

Elisabeth Coyne http://orcid.org/0000-0001-8511-600X

Karin Brochstedt Dieperink http://orcid.org/0000-0003-4766-3242

\section{REFERENCES}

1 Forero R, Nahidi S, de Costa J, et al. Perceptions and experiences of emergency department staff during the implementation of the four-hour rule/national emergency access target policy in Australia: a qualitative social dynamic perspective. BMC Health Serv Res 2019;19:82.

2 Statusrapport. Sundhedsstyrelsen, Danske Regioner, and Sundheds OG AEldreministeriet, de danske akutmodtagelser, 2016, 2017.

3 Han C-Y, Barnard A, Chapman H. Discharge planning in the emergency department: a comprehensive approach. J Emerg Nurs 2009;35:525-7.

4 Nielsen LM, Gregersen Østergaard L, Maribo T, et al. Returning to everyday life after discharge from a short-stay unit at the emergency Department-a qualitative study of elderly patients' experiences. Int J Qual Stud Health Well-being 2019;14:1563428.

5 Stevens L, Fry M, Browne M, et al. Fast track patients' satisfaction, compliance and confidence with emergency department discharge planning. Australas Emerg Care 2019;22:87-91.

6 Vaillancourt S, Seaton MB, Schull MJ, et al. Patients' Perspectives on Outcomes of Care After Discharge From the Emergency Department: A Qualitative Study. Ann Emerg Med 2017;70:648-58.

7 Kremers MNT, Zaalberg T, van den Ende ES, et al. Patient's perspective on improving the quality of acute medical care: determining patient reported outcomes. BMJ Open Qual 2019;8:e000736.

8 Lisby M, Klingenberg M, Ahrensberg JM, et al. Clinical impact of a comprehensive nurse-led discharge intervention on patients being discharged home from an acute medical unit: randomised controlled trial. Int J Nurs Stud 2019;100:103411.

9 Levine DM, Ouchi K, Blanchfield B, et al. Hospital-Level care at home for acutely ill adults: a randomized controlled trial. Ann Intern Med 2020;172:77-85.

10 Johannessen A-K, Steihaug S. Municipal acute units as part of the clinical pathway for older patients. Int J Integr Care 2019;19:2.

11 Hoffmann E, Olsen PR. Like an ACE up the sleeve: an interview study of nurses' experiences of the contact with relatives in a somatic emergency ward. Scand J Caring Sci 2018;32:1207-14.

12 Elmqvist C, Frank C. Patients' strategies to deal with their situation at an emergency department. Scand J Caring Sci 2015;29:145-51.

13 Mackie BR, Marshall A, Mitchell M. Acute care nurses' views on family participation and collaboration in fundamental care. J Clin Nurs 2018;27:2346-59.

14 Mackie BR, Mitchell M, Marshall AP. Patient and family members perceptions of family participation in care on acute care wards. Scand J Caring Sci 2019;33:359-70.

15 Demidenko J, Routasalo P, Helminen M, et al. Family functioning evaluated by family members of older patients and nurses in emergency departments. Scand J Caring Sci 2018;32:1064-73.

16 Cetin-Sahin D, Ducharme F, McCusker J, et al. Experiences of an emergency department visit among older adults and their families: qualitative findings from a mixed-methods study. J Patient Exp 2020;7:346-56.

17 Hsiao P-R, Redley B, Hsiao Y-C, et al. Family needs of critically ill patients in the emergency department. Int Emerg Nurs 2017;30:3-8

18 Curran J, Cassidy C, Chiasson D, et al. Patient and caregiver expectations of emergency department care: a scoping literature review. Int Emerg Nurs 2017;32:62-9.

19 Simonsen J, Robertson T. Routledge international Handbook of participatory design. Routledge, 2012.

20 Clemensen J, Rothmann MJ, Smith AC, et al. Participatory design methods in telemedicine research. J Telemed Telecare 2017;23:780-5

21 Østervang C, Lassen AT, Jensen CM, et al. How to improve emergency care to adults discharged within 24 hours? acute care planning in emergency departments (the ACE study): a protocol of a participatory design study. BMJ Open 2020;10:e041743.

22 Tong A, Sainsbury P, Craig J. Consolidated criteria for reporting qualitative research (COREQ): a 32-item checklist for interviews and focus groups. Int J Qual Health Care 2007;19:349-57.

23 DEPT. User manuel Danish emergency process triage - DEPT, 2021. Available: http://deptriage.dk/brugervejledning/

24 Moser A, Korstjens I. Series: practical guidance to qualitative research. Part 3: sampling, data collection and analysis. Eur J Gen Pract 2018;24:9-18.

25 Green J, Thorogood N. Qualitative methods for health research. 3 edn. Sage, 2014.

26 Abalos EEet al. Husserlian phenomenology and colaizzi's method of data analysis: exemplar in qualitative nursing inquiry using nursing as caring theory. Int J Hum Caring 2016;20:19-23.

27 Spradley J, Observation P. Long Grove. waveland Press, 2016.

28 Kvale S, Brinkmann S. Interview: introduktion TIL et håndværk. Kbh: Hans Reitzel, 2009.

29 Malterud K. Kvalitative metoder I medisinsk forskning. Osla: Univeristetsforlaget, 2014.

30 Sykepleiernes Samarbeid i Norden Northern Nurses' Federation. Ethical guidelines for nursing research in the Nordic countries, 2003.

31 Bittencourt RJ, Stevanato AdeM, Bragança CTNM, et al. Interventions in overcrowding of emergency departments: an overview of systematic reviews. Rev Saude Publica 2020;54:66.

32 De Freitas L, Goodacre S, O'Hara R, et al. Interventions to improve patient flow in emergency departments: an umbrella review. Emerg Med J 2018;35:626-37.

33 Rising KL, Powell RE, Cameron KA, et al. Development of the uncertainty communication checklist: a patient-centered approach to patient discharge from the emergency department. Acad Med 2020;95:1026-34.

34 Samuels-Kalow M, Rhodes K, Uspal J, et al. Unmet needs at the time of emergency department discharge. Acad Emerg Med 2016;23:279-87.

35 Samuels-Kalow ME, Stack AM, Porter SC. Effective discharge communication in the emergency department. Ann Emerg Med 2012:60:152-9. 
36 Rising KL, Hudgins A, Reigle M, et al. "I'm Just a Patient": Fear and Uncertainty as Drivers of Emergency Department Use in Patients With Chronic Disease. Ann Emerg Med 2016;68:536-43.

37 Graham B, Endacott R, Smith JE, et al. 'They do not care how much you know until they know how much you care': a qualitative metasynthesis of patient experience in the emergency department. Emerg Med J 2019;36:355-63.

38 Jensen CM, Santy-Tomlinson J, Overgaard S, et al. Empowerment of whom? the gap between what the system provides and patient needs in hip fracture management: a healthcare professionals' lifeworld perspective. Int J Orthop Trauma Nurs 2020;38:100778.

39 Barreto MdaS, Garcia-Vivar C, Santos JLGD, et al. Meanings attributed by family and patients to family presence in emergency rooms. Rev Bras Enferm 2019;72:1684-91.
40 Forsgärde E-S, From Attebring M, Elmqvist C. Powerlessness: dissatisfied patients' and relatives' experience of their emergency department visit. Int Emerg Nurs 2016;25:32-6.

41 Naef R, Kaeppeli BM, Lanter R, et al. Implementing family systems care through an educational intervention with nurses and midwives in obstetrics and gynecological care: a mixed-methods evaluation. $J$ Fam Nurs 2020;26:138-52.

42 Wright LM, Leahey M. Maximizing time, minimizing suffering: the 15-Minute (or less) family interview. J Fam Nurs 1999;5:259-74.

43 Emmamally W, Erlingsson C, Brysiewicz P. Partnering with families: is the ED ready? Int Emerg Nurs 2019;42:1.

44 Korstjens I, Moser A. Series: practical guidance to qualitative research. Part 4: Trustworthiness and publishing. Eur J Gen Pract 2018;24:120-4 